\title{
Influence of Thermal Oxidation Temperatures on the Structural and Morphological Properties of $\mathrm{MoO}_{3}$ Thin Films
}

\author{
A. Hojabri*, F. Hajakbari, A. Emami Meibodi and M.A. Moghri Moazzen \\ Department of Physics, Karaj Branch, Islamic Azad University, Karaj, Iran
}

\begin{abstract}
In this study, molybdenum (Mo) thin films have been deposited on Si substrate by dc magnetron sputtering. Then for preparation of $\mathrm{MoO}_{3}$ thin films the thermal oxidation of Mo thin films under the oxygen flow was employed in the electrical furnace. The influence of the different thermal oxidation temperatures at $400,600,800$ and $1000{ }^{\circ} \mathrm{C}$ on the structural and morphological properties of $\mathrm{MoO}_{3}$ thin films were characterized by X-ray diffraction and atomic force microscopy, respectively. The results show that the crystallinity and surface morphology of the films are strongly dependent on the thermal oxidation temperatures.
\end{abstract}

DOI: 10.12693/APhysPolA.123.307

PACS: 61.05.cp, 68.37.Ps, 68.55.J-, 65.40.-b

\section{Introduction}

Molybdenum oxide $\left(\mathrm{MoO}_{3}\right)$ is a metal oxide with intermediate band gap $n$-type semiconductors that have attracted much interest for technological applications in recent years, because of its attractive structural, electrical and optical properties [1].

Also, $\mathrm{MoO}_{3}$ thin films have potential application in important devices, including optical memories [2], gas sensors [3], catalysis [4], electrochromic devices (ECDs) [5] and lithium batteries [6]. However, the device efficiency is essentially related to the structure and surface morphology of the films which in turn invariably depends on the deposition technique and deposition parameters used for the growth of thin films.

In the present investigation the thermal oxidation of Mo thin films was employed for preparation of $\mathrm{MoO}_{3}$ thin films. The effect of thermal oxidation temperatures on structural and surface morphology of the films are elaborately studied and presented here.

\section{Experimental details}

In this experiment, in the first step the Mo thin films were deposited by dc magnetron sputtering onto silicon $(1 \mathrm{~cm} \times 1 \mathrm{~cm})$ substrates at room temperature with using a molybdenum target (purity 99/995\%). The distance between substrate and target is $7 \mathrm{~cm}$. Before the operation, the chamber is evacuated to less than $4 \times 10^{-5}$ Torr, by means of a rotary and diffusion pumps. The pure argon gas is injected to the system as working gas to deposit the films with discharge current of $180 \mathrm{~mA}$. The films depositions are carried out for 24 min at constant gas pressure of $2 \times 10^{-2}$ Torr. The thickness of the films and the rate of deposition were controlled using the quartz crystal monitor. The rate of sputtering $(1 \AA / \mathrm{s})$ was used to

*corresponding author; e-mail: hojabri@kiau.ac.ir deposit all Mo films to a thickness of $140 \mathrm{~nm}$. Then, for preparation of $\mathrm{MoO}_{3}$ thin films the thermal oxidation of Mo films under the oxygen flow at different temperatures, namely $400,600,800$ and $1000^{\circ} \mathrm{C}$ were done in electrical furnace. Finally, the effect of the thermal oxidation temperatures on the structures and surface morphology of the prepared films were investigated.

\section{Results and discussion}

X-ray diffraction (XRD) patterns of the thin films at different thermal oxidation temperatures were shown in Fig. 1.

The X-ray diffraction patterns showed that for sample without thermal oxidation, only one intensive peak due to the Mo (110) was observed. Thermal oxidation of Mo films at $400{ }^{\circ} \mathrm{C}$ showed three peaks due to the Mo (110), (211) and (220) orientations. By increasing the temperature to $600{ }^{\circ} \mathrm{C}$ the polycrystal $\mathrm{MoO}_{3}$ phase appeared. Furthermore, by enhancing the thermal oxidation temperatures up to $1000{ }^{\circ} \mathrm{C}$ the crystallinity of $\mathrm{MoO}_{3}$ films was decreased, maybe for disassembled lattice arrangement. The results show that the optimum temperature of thermal oxidation of Mo films in our experiment was $600{ }^{\circ} \mathrm{C}$, because in this temperature the best crystallinity was observed. The average crystallite sizes were estimated by the Scherrer formula [7]. The measured values were varied between $12-42 \mathrm{~nm}$ for the samples (1-5) as are mentioned in Table I.

Figure 2 shows the AFM images of the thin films at different thermal oxidation temperatures. Investigation of the AFM images demonstrates that before the thermal oxidation, the crystal sizes are small. By thermal oxidation at $400^{\circ} \mathrm{C}$, these small crystals gradually combine and make bigger grains. With increasing the thermal oxidation temperature to $600^{\circ} \mathrm{C}$, the grains become bigger and at last it can cause to create clusters. The films roughness also increases during the annealing pro- 


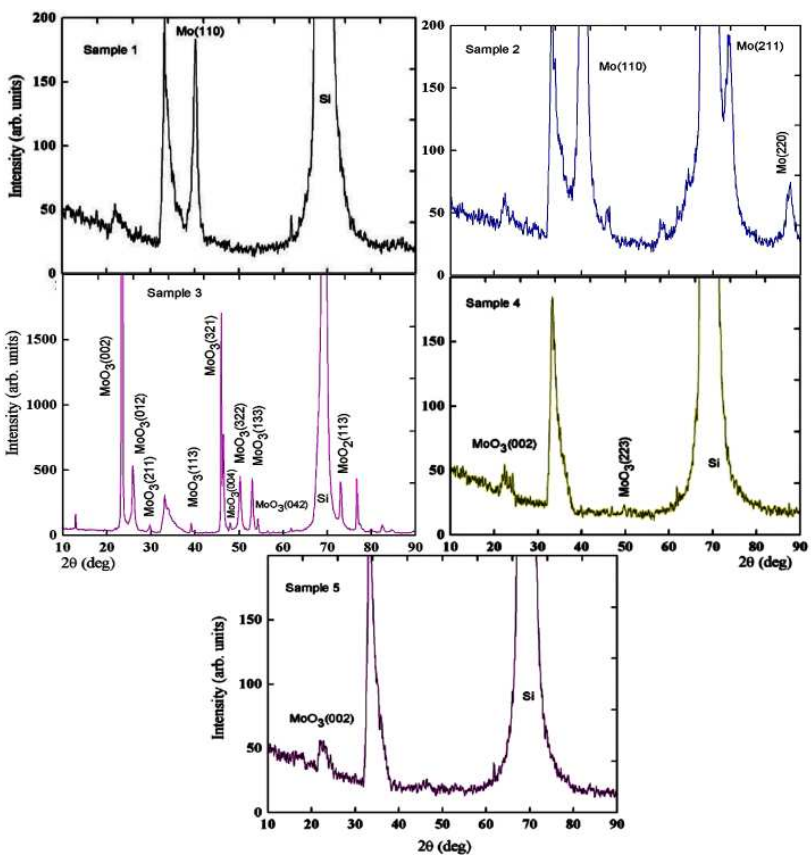

Fig. 1. XRD patterns of the thin films at different thermal oxidation temperatures: sample (1): without oxidation, sample (2): $400{ }^{\circ} \mathrm{C}$, sample (3): $600{ }^{\circ} \mathrm{C}$, sample (4): $800{ }^{\circ} \mathrm{C}$, sample $(5): 1000^{\circ} \mathrm{C}$.

\section{TABLE I}

Crystal size and crystal phase of films.

\begin{tabular}{c|c|c}
\hline \hline $\begin{array}{c}\text { Sample } \\
\text { number }\end{array}$ & $\begin{array}{c}\text { Crystal phase } \\
(h k l)\end{array}$ & $\begin{array}{c}\text { Average } \\
\text { crystal size } \\
{[\mathrm{nm}]}\end{array}$ \\
\hline 1 & $\mathrm{Mo}(110)$ & 21.53 \\
2 & $\mathrm{Mo}(110)$ & 30.79 \\
3 & $\mathrm{MoO}_{3}(002)$ & 41.35 \\
4 & $\mathrm{MoO}_{3}(002)$ & 34.45 \\
5 & $\mathrm{MoO}_{3}(002)$ & 12.87
\end{tabular}

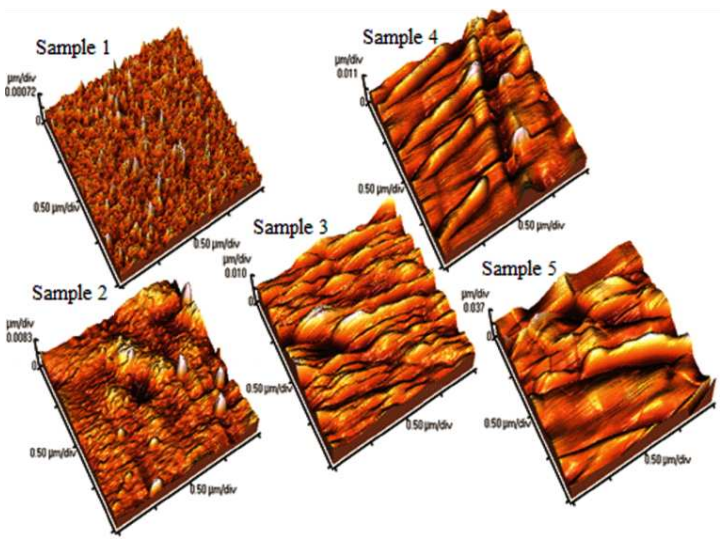

Fig. 2. AFM images of samples: sample (1): without oxidation, sample $(2): 400{ }^{\circ} \mathrm{C}$, sample $(3): 600{ }^{\circ} \mathrm{C}$, sample (4): $800{ }^{\circ} \mathrm{C}$, sample (5): $1000^{\circ} \mathrm{C}$.
TABLE II

RMS roughness and Ave roughness of films.

\begin{tabular}{c|c|c}
\hline \hline $\begin{array}{c}\text { Sample } \\
\text { number }\end{array}$ & $\begin{array}{c}\text { RMS roughness } \\
{[\mathrm{nm}]}\end{array}$ & $\begin{array}{c}\text { Ave roughness } \\
{[\mathrm{nm}]}\end{array}$ \\
\hline 1 & 0.14 & 0.11 \\
2 & 2.44 & 1.91 \\
3 & 5.11 & 3.93 \\
4 & 1.68 & 1.18 \\
5 & 2.21 & 1.59
\end{tabular}

cess. Table II shows root mean square (RMS) roughness and average (Ave) roughness of films.

\section{Conclusion}

$\mathrm{MoO}_{3}$ films have been formed by thermal oxidation of Mo film which has been sputtered on silicon substrate. The results have shown that the effect of thermal oxidation temperatures on $\mathrm{MoO}_{3}$ films leads to thermal oxidation of Mo films at $400{ }^{\circ} \mathrm{C}$ which promotes the crystallinity of Mo film and by increasing the oxidation temperature up to $600{ }^{\circ} \mathrm{C}$ the polycrystalline $\mathrm{MoO}_{3}$ film appeared. Furthermore, by enhancing the thermal oxidation temperatures up to $1000^{\circ} \mathrm{C}$ the $\mathrm{MoO}_{3}$ films crystallinity was decreased, maybe for the disassembled lattice arrangement. The results show that the optimum temperature of thermal oxidation of Mo films in our experiment was $600^{\circ} \mathrm{C}$. AFM results showed the lowest RMS roughness, for Mo films without oxidation, and the highest RMS roughness for the polycrystalline $\mathrm{MoO}_{3}$ film.

\section{Acknowledgments}

This work was financially supported by the Islamic Azad University, Karaj Branch.

\section{References}

[1] N. Miyata, S. Akiyoshi, J. Appl. Phys. 58, 1651 (1985)

[2] E. Fortunato, D. Ginley, H. Hosono, D.C. Paine, MRS Bull. 32, 242 (2007)

[3] D. Manno, M.D. Giulio, A. Serra, T. Siciliano, G. Micocci, J. Phys. D, Appl. Phys. 35, 228 (2002)

[4] C.A. Ellefson, O. Marin-Flores, Su Ha, M. Grant Norton, J. Mater. Sci. 47, 2057 (2012)

[5] T. Aoki, T. Matsushita, K. Mishiro, A. Suzuki, M. Okuda, Thin Solid Films 517, 1482 (2008)

[6] H. Ohtsuka, Y. Sakurai, Solid State Ion. 144, 59 (2001).

[7] B.D. Cullity, Elements of X-ray Diffractions, Addison-Wesley, Reading MA 1978, p. 102. 